\title{
Medical Thoracoscopy at 105. Anniversary
}

\author{
Muzaffer Metintaş ${ }^{1,2}$
}

${ }^{1}$ Eskişehir Osmangazi University Lung and Pleural Cancers Research and Clinical Center, Eskişehir ${ }^{2}$ Department of Chest Diseases, Eskişehir Osmangazi University Faculty of Medicine, Eskişehir

\begin{abstract}
Medical thoracoscopy (MT) for cases of exudative pleural effusion without a diagnosis by either clinical, radiological, laboratory or cytological investigation is performed as an established diagnostic method for the diagnosis of pleural diseases which has been performed routinely in many clinics. MT was done mainly with a rigid thoracoscope under mild sedation and local anesthesia in an endoscopy room with basic monitoring. It allows for the direct inspection of the pleural space and biopsies taken under direct vision. The diagnostic yield is in the order of $90-95 \%$ for malignant disease and can be as high as $100 \%$ for pleural tuberculosis. Additionally, MT can be performed for therapeutic as well as diagnostic purposes. Although MT remains an invasive procedure, complications are infrequently seen. Due to both the advantages of MT and the gradually increasing incidence of mesothelioma and malignant pleural disease, the use of MT for pleural effusions will be increasing in pulmonary clinics in coming years. Additionally MT will have some new developments; such as semirigid thoracoscopy, florescent or auto-florescent thoracoscopy, narrow-band imaging, thoracoscopy in patients without pleural effusion.
\end{abstract}

Keywords: Diagnosis, medical thoracoscopy, pleura

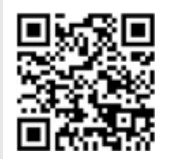

Received Date: 22.02 .2015 Accepted Date: 27.04.2015 Available Online Date: 04.06 .2015

DOI: 10.5152/ejp.2015.47550

Corresponding Author Muzaffer Metintas

E-mail: muzaffermetintas@gmail.com

-Available online at www.eurasianjpulmonol.com

This work is licensed under a Creative Commons Attribution-NonCommercial 4.0 International License.

\section{INTRODUCTION}

Medical thoracoscopy (MT) is a medical technique that can be used for diagnosing pleural pathologies accompanied by pleural fluids requiring tissue sampling-histopathological examination, but not diagnosed with clinical, radiological, and laboratory evaluations. It can also be used for palliative treatment in special cases. MT is performed under local anesthesia and mild/conscious sedation in an endoscopy room. It is a safe, highly efficient, and low-cost procedure (1-3). The use of MT in the department of chest diseases has rapidly become widespread because it allows outpatient care, it can also be used in patients without pleural fluid under the guidance of ultrasonography, and it can be implemented with developing imaging techniques such as semirigid thoracoscopy, autofluorescence thoracoscopy, and narrow-band imaging.

\section{History}

Thoracoscopy was firstly defined, implemented, and introduced into the medical literature by Dr. Hans Christian Jacobaeus, a Swedish internal medicine specialist, in 1910 (4). There is no distinct difference between the procedure introduced then and the procedure called MT at present, except technical developments during the last 105 years.

Historical development of thoracoscopy is as follows according to chronological course:

- 1910: Definition of thoracoscopy and first practices (Dr. HC Jacobaeus).

- 1920-1950: The period when "Jacobaeus operations" was becoming widespread (Before 1950, the procedure was performed by an internal medicine physician. In those years, the subject of chest diseases was not a separate discipline. The name of the procedure was "thoracoscopy", but in 1923, a group from France used the name "pleuroscopy" for the procedure in their study).

- 1950-1970: The period in which tuberculosis pleurisy occurred as a common disease after the Second World War, the success rate of diagnosis with needle biopsies reached up to $70 \%$, the use of thoracoscopy decreased, and the use of Abrams and other pleural needle biopsies increased (5). 
- 1970-1990: Decreased prevalence of tuberculosis, the prominence of cancer, and re-increasing use of thoracoscopy because of the insufficiency of pleural needle biopsies in the diagnosis of cancer (after 1970, the procedure was again named as "thoracoscopy").

- 1991: Definition of videothoracoscopic surgery (VATS) in thoracic surgery.

- $\quad$ 1995: Following the spread of VATS, usage indications were differentiated between internal medicine specialists and thoracic surgeons and thoracoscopy was divided into two definitions as "MT" and "VATS" for preventing conflicts; thus, MT was used for the first time $(6,7)$.

- 2002: Development and application of semirigid thoracoscopy (8).

- 2010: Development and application of mini-thoracoscopy (9).

- 2013: Initiation of MT applications in outpatients (10).

- 2014: Use of MT in patients without pleural fluid under the guidance of ultrasonography (11).

To date, several atlases, books, and evidence-based guidelines have been published on MT $(2,3,7,12-20)$.

In our country, the first use of MT by pulmonologists in the Department of Chest Diseases dates back to approximately 42 years. In 1973, the use of MT was initiated to be used both by the Hacettepe University and Dicle University. The first scientific study on MT in Turkey was reported in the thesis by Dr. Yaşar Özercan from the Dicle University. This thesis study was presented in the $14^{\text {th }}$ Turkish Tuberculosis Congress in Samsun in 1979 (21), and a team from the Hacettepe University had their study published as two articles $(22,23)$.

Then, in 1994, MT was initiated to be applied in the Department of Chest Diseases in the Faculty of Medicine at the Eskişehir Osmangazi University, and it has since then been used as a diagnostic method for more than 20 years (24-26).

After the applied courses organized in our country between the 2008 and 2012, new health centers started to use MT. On the other hand, semirigid thoracoscope was first used in the İstanbul Yedikule Chest Diseases and Chest Surgery Training and Research Hospital (27).

\section{Definition}

To differentiate between MT, which is used for diagnosis and palliative treatment, and VATS, which is used primarily for pleural and pulmonary surgeries and in special cases, for the diagnosis of pleural and/or pulmonary diseases, with regard to purpose and procedure, the name of "pleuroscopy" is used instead of the name "MT" by some authors. At this point, the use of "MT" for routine rigid thoracoscopy procedures is more appropriate because this procedure includes palliative treatment interventions such as monitoring the pleural space in detail, taking biopsy when necessary, performing pleurodesis in suitable cases, opening adherences in malignant fluids and empyema, and closing fistula. On the other hand, "pleuroscopy" is a procedure that is performed only for establishing diagnosis. This name can probably be used for mini-thoracoscopy, which will be mentioned later. With the functions stated above, MT is completely differentiated from VATS, which is performed with many incisions and processes under general anesthesia in the operating room (Table 1). In fact, VATS is a procedure for therapeutic purposes rather than for diagnostic purposes. With VATS, major surgical procedures, including lobectomy, are successfully conducted (28-30).

\section{Medical Thoracoscopy for Diagnostic Purpose}

Because of its high diagnostic efficiency, MT is commonly used for the diagnosis of malignant pleural involvement and tuberculosis pleurisy requiring specific histopathological diagnosis for the differential diagnosis of benign asbestos pleurisy and rheumatoid arthritis in which macroscopic monitoring is very important and also for the diagnosis of clinical conditions such as paramalignant fluid and drug-induced fluid in which malignant pleural involvement must be ruled out (Figure 1).

In all of the recently published international guidelines, the use of MT under these defined indications is stated and its use is recommended $(3,7,13)$.

Table 1. The differences between the implementations of MT and videothoracoscopy

\begin{tabular}{|l|l|l|}
\hline Procedure & Videothoracoscopy & Medical thoracoscopyy \\
\hline Place & Operating room & Endoscopy room \\
Anesthesia & Specialist in chest surgery & Specialist in chest diseases \\
Indication & General & Local \\
& Multiple holes & Single hole \\
& $\begin{array}{l}\text { Primary } \\
\text { Stapler lung biopsy } \\
\text { Nodule resection }\end{array}$ & Primary \\
& $\begin{array}{l}\text { Secondary } \\
\text { Lobectomy } \\
\text { Opening pericardial window } \\
\text { Pleural biopsy } \\
\text { Pleural drainage }\end{array}$ & $\begin{array}{l}\text { Pleural biopsy } \\
\text { Pleurodesis }\end{array}$ \\
Pleural drainage \\
\hline
\end{tabular}





Figure 1. a-d. The image of normal pleural space in MT: P, parietal pleura; D, diaphragm; arrow, intercostals vessel (a). Typical plastic (fibrous) shaggy nodules in a case with rheumatoid arthritis (b); benign asbestos pleurisy; pleural thickening with similar typical fibrotic appearance in both visceral pleura and parietal pleura and partially fibrous plaques in parietal pleura (c). Malignant nodules on the parietal pleura and the lung in a patient with mesothelioma (arrow); P and Pr parietal pleura; Vi visceral pleura, D diaphragm; L lung (d)

In clinical series, the diagnostic sensitivity of MT is reported to be above $90 \%$, and its specificity is reported to be up to $100 \%$ (31-36). In a large case series, the diagnostic sensitivity of MT was presented to be similar to that of VATS (30). Although there is no randomized study directly comparing MT and VATS, it is generally accepted that MT performed under local anesthesia and mild sedation has diagnostic sensitivity similar to VATS based on the data mentioned above. The diagnostic success of MT is reported to be a little lower (approximately $85 \%-90 \%$ ) in early-stage malignant mesothelioma cases because of unique pleural distribution of a tumor or the partial development of fibrosis on tumor, and the diagnostic success of MT is reported to be above $90 \%$ in general case series $(24,35,37)$.

Contraindications for MT are quite limited. Absolute contraindication is seen in special cases such as the absence of sufficient gap in the pleural space, presence of intense adherences, comatose or unconscious patient, type 2 severe respiratory failure, superior vena cava syndrome, severe pulmonary hypertension, end-stage pulmonary fibrosis, and patients refusing the procedure. For the procedure to be performed, there must be sufficient space for MT to be able to turn laterally in the pleura. For this, $10 \mathrm{~cm}$-space is enough. Other contraindications are relative and can be corrected. If they are corrected, the procedure can be performed (2).

Medical thoracoscopy is a safe technique. Although it has some side-effects, its mortality and morbidity rates are not higher than those of closed pleural biopsy or transthoracic biopsy $(26,34)$. In patients for whom MT is performed carefully after a good preparation of the procedure, serious complications are rarely seen. Some studies reported the rate of major complications, including prolonged air leak, subcutaneous emphysema, and entry site infection as 3\%-4\%, and the rate of minor complications such as pain and hypotension as $8 \%-14 \%$, and mortality rate as $0.01 \%-0.24 \%$. In some series, no mortality was reported $(2,31-36)$.

Some conditions may increase the risk for the development of side-effects in MT. These conditions are advanced age, chronic obstructive pulmonary disease, heart failure, renal failure, uncontrolled atrial fibrillation, cerebrovascular diseases, insulin-dependent diabetes mellitus, low performance, valvular heart disease, and splenectomy (2). The effect of these risk-increasing factors can be reduced with necessary additional support. In a study in which 355 patients who underwent MT were compared after dividing them into two groups as high-risk patients and normal-risk patients for complications, the most common complication was found to be pain (12.3\%) in the high-risk group, the rate of which was significantly higher than that found the normal-risk group (27).

As a result, routinely applied MT has lower morbidity and mortality rates, but similar diagnostic efficiency compared with open biopsy procedures (31, 34-36). Because of lower risk for vascular and pulmonary trauma, MT is accepted to be a safer process than closed pleural needle biopsy (36). Many authors report that similar to flexible bronchoscopy, MT can be easily learned and is also safe and cheap; however, it is a technique with higher diagnostic efficiency than flexible bronchoscopy (31-36). In the United Kingdom, it was calculated that MT for diagnostic purposes had lower cost, resulting in a decrease by $£ 1.527$ per case (31). MT is commonly used in larger hospitals in European countries, and its usage is increasing with time. In the United Kingdom, although MT was used in 11 health centers in 1999, the number of centers where it was used increased to 17 in 2004 and to 37 in 2009 (3). Its usage in USA is becoming widespread gradually, and its use in outpatients and in patients without fluid has recently been recommended $(10,11)$.

\section{Medical Thoracoscopy for Therapeutic Purpose}

Usage areas of MT for therapeutic purpose can be evaluated under the following three headings: pleural fluid drainage, pleurodesis, and easing the pleural space by opening adherences in the pleural space, particularly empyema $(2,3,38,39)$.

During MT procedure, a high amount of pleural fluid can be drained with a lower risk of pulmonary edema. When the presence of malignant pleural pathology in the pleural space is ensured in the process, pleurodesis with talc can be performed easily and efficiently (40). Some health centers suggest that pleurodesis with MT is more efficient than pleurodesis performed with the slurry method through a chest tube (41).

Medical thoracoscopy can be useful in parapneumonic pleurisy (PPP) for opening pleural adherences and fibrous bands and in malignant pleural pathologies for making pleurodesis more efficient. In malignant pleural fluids, because bleeding occurs between the pleural leaves in the presence of a history of previous thoracentesis or pleural needle biopsy performed several times, fibrotic activity develops with clotting and adherences and fibrous bands occur. Even if the fluid is drained in patients, the lung below may not expand and an efficient pleurodesis process may not be performed. In this case, if the lung expands after opening adherences through MT, pleurodesis can be performed.

During invasive procedures, such as closed pleural needle biopsy, thoracentesis, and drainage of high quantities of pleural fluid, the lung can be injured. Although rare, prolonged pneumothorax can be encountered. Sometimes, patients with chronic bronchopleural fistula may apply. In both cases, fistula is found during MT and cicatrix tissue is formed by coagulating it from the periphery to the center with cautery. Subsequently, the fistula is closed. However, large fistulas must be dealt with VATS. 
Medical Thoracoscopy in the Treatment of Parapneumonic Pleurisy The first known endoscopic procedure for PPP was performed by Dr. Richard Cruise in 1866. Dr. Cruise entered through the fistula using a cystoscope in an 11-year-old girl having chronic empyema fistulized on the chest wall and monitored the pleural space (39).

Parapneumonic pleurisy treatment has the following three fundamental principles: 1 . The treatment of infection; 2. Drainage of purulent fluid and opening of the adherences and bands, thereby providing lung expansion; and 3. Prevention of complications and progression to chronic stage.

It is important to find answers for the following questions to achieve the requirements of the abovementioned principles: Which technique will be used for drainage? What can be done in the presence of adherences? Is fibrinolytic therapy necessary? Is surgical treatment necessary? If yes, which technique is used and when?

Medical thoracoscopy is an efficient treatment technique that will provide accurate and successful drainage by opening adherences when used in a timely manner in the treatment of PPP, thereby allowing the placement of an appropriate tube (Figure 2$)(3,38,39,42)$.

According to the data obtained from the studies that have been conducted to date, MT has various usage indications in different clinics $(38,39,42,43)$ :

- For accurate placement of the drain just before the placement of a chest tube,

- For re-positioning the drain if a successful drainage does not begin within 2-3 days after the insertion of the drain, and

- For re-obtaining the pleural space by opening partial adherences in the pleural space.

The abovementioned points can be easily achieved owing to the advantages of MT. The advantages are as follows:

- It can be performed under local anesthesia and mild sedation,

- It can also be implemented in patients with poor general health status,

- It can diagnose the underlying conditions such as underlying tumor and foreign body,

- It provides short duration of hospitalization,

- It is inexpensive,

- It is performed with a small and single wound site.

With these advantages, the success rate of MT in empyema treatment is the same with VATS, which is reported to range between $73 \%$ and $100 \%(38,39,42,43)$.
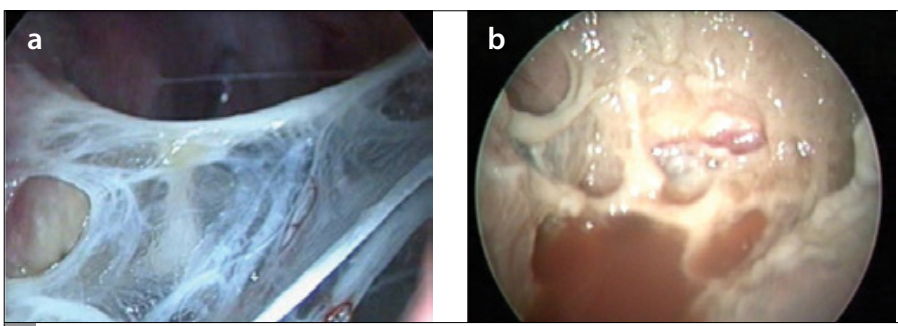

Recently, there is a tendency to consider MT prior to fibrinolytics in the treatment of PPP. Because most of the studies showed that performing MT at the time of the occurrence of adherences in the pleural space provides a more efficient treatment than single tubes and fibrinolytics $(3,39)$. In a large series, 127 patients were treated with MT and the success rate was reported to be $91 \%$ (44). In a series including 41 cases, MT was found to be successful at the rate of $85 \%$ in multilocular fluid of nine patients having free fluid depending on the state of the pleural space and $50 \%$ in organized patients (38).

The entry site for MT must be determined through ultrasonography just before the procedure (39). After the thoracoscope enters, fluid aspiration is performed slowly and carefully. Fluid aspiration can be restricted because of pouches and adherences. After the fluid in a pouch is completely finished, the adherences are opened with forceps or adhesion scissors and pouches are disappeared. Meanwhile, the fluid is liberated from the opened pouches. Because the field of vision is narrowed with increasing amount of released fluid, this fluid must be aspirated. As the adherences are opened and the pouches are emptied, the pleura becomes a single space. Because parietal and visceral pleura is thick and covered with infectious material, it becomes difficult to observe the lung below; the lung is usually collapsed. In such a case, thick infectious material on the lung is carefully taken using forceps for opening the surface of the lung. If a suspected tumor-like structure is observed while working on the pleural space, sufficient biopsy must be taken from that area. After assuring that the pleural space has been adequately drained, a thick tube $(28 \mathrm{~F})$ is inserted and the pleural space is exited $(38,39,42)$. Twelve hours after the process, fibrinolytic treatment can be administered through the tube. It is accepted that fibrinolytic practice increases the success of treatment (44-46).

In PPP, because therapeutic MT for opening adherences lasts longer than diagnostic procedures, local anesthesia and sedation interval should be paid attention. This process can be performed with VATS in the clinics not having the opportunity of MT. During the procedure of VATS, partial decortication can also be performed (47). In patients with mediastinitis, surgical treatment is absolutely needed.

\section{CURRENT PRACTICES IN MT}

\section{Semirigid Thoracoscopy}

Semirigid thoracoscope is a pleural endoscope, including both flexible and rigid features. Owing to its features, it can be used for diagnostic purposes. In this form, it is an endoscope warranting the definition of "pleuroscope". The first model of semirigid thoracoscope was brought into use in 1997, and the model, which is used at present, was developed in 2002 (8).

The hand-held upper part of the device is rigid, located 5-cm apart, which is suitable for maneuver during the process, and is flexible. The
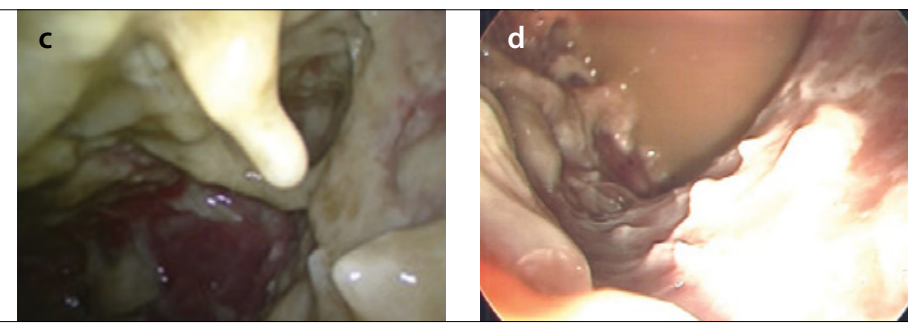

Figure 2. a-d. After A thoracoscope is entered, adherences are opened (a), pus is drained (b), the pleura is attempted to be converted into a single space by opening pouches (c), a single space is formed for the insertion of tube (d) 
thickness of the distal tip of the device is $7 \mathrm{~mm}$, the width of working channel is $2.8 \mathrm{~mm}$, and its tip can be rotated up to 130-160 degree to the upper and lower directions. Its biopsy forceps are similar to fiberoptic bronchoscope forceps. It can work in association with the endoscopic system as well as with a videobronchoscope. Therefore, its installation is very easy and the cost of equipment is low.

The most important advantage of semirigid thoracoscope is that it has the body of a fiberoptic bronchoscope, to which specialists in chest diseases are accustomed. Therefore, problems related to early learning period are not encountered during manipulations in practices.

Biopsies taken with flexible forceps are generally sufficient for histopathological diagnosis. However, in the case of fibrous thickening in the pleura, more biopsies must be taken by entering deeply from the same point. The disadvantage of semirigid thoracoscope is that it cannot efficiently open the fibrous adherences in the pleural space. Therefore, its use in patients with pleural adherence and thickening is risky.

In a study involving semirigid thoracoscopy including a series of 150 cases conducted in 2010 , the sensitivity was $87 \%$, the specificity was $100 \%$, and accuracy was $91 \%$ (48). In an extensive review article by the same authors regarding semirigid thoracoscopy, positive likelihood ratio (LR+) was 5.47 and negative likelihood ratio (LR-) was 0.08 (49). Both values indicate that this procedure is highly useful for determining the presence or absence of disease. In the same study, the sensitivity and specificity were revealed to be $95 \%$ and $100 \%$, respectively. It was stated in this review that no 30-day mortality and no major complication developed.

For specialists in chest diseases, semirigid thoracoscope seems to be an area of interest that will increase ambulatory care facilities in the diagnosis of pleural diseases.

\section{Mini Thoracoscopy}

In the thoracoscopy used in routine patient processes, a trocar with external diameter of $10 \mathrm{~mm}$ is used. However, there are systems suitable for the entry of a trocar with a diameter of $7 \mathrm{~cm}$, and even of 5 $\mathrm{cm}$. Recently, a system having a trocar with a diameter of $3 \mathrm{~mm}$, and even of $3 \mathrm{~mm}$, has been produced. This system is called "mini-thoracoscopy".

The devices of mini-thoracoscopy are smaller and gentler for being suitable for an external diameter of $3 \mathrm{~mm}$. This sensitivity requires entering through two holes during the procedure. Diagnosis sampling is performed by sending a thoracoscope or optic through one hole and forceps through the other hole. The diagnostic success rate was reported to be $93 \%$ in two series in which thoracoscope was used $(9,50)$.

The most important advantage of mini-thoracoscope is that it is quite easy and comfortable for patient under local anesthesia. Particularly in recent days, it seems as a promising method for ambulatory thoracoscopy process such as semirigid thoracoscopy. However, the fact that it is thin and sensitive can cause difficulties in opening pleural adherences, and it is difficult to be used for therapeutic purposes. Moreover, its equipment is more fragile and more expensive for simple physical traumas than normal thoracoscope.

\section{Fluorescent/Autofluorescent Thoracoscopy}

Fluorescent/autofluorescent technique is based on the appearance of malignant involvement of mucosal regions in different colors in endoscopy procedures (51).
In fluorescent technique, because of its different emission feature, when filtrated ultraviolet rays are implemented on the tissue, malignant tumoral regions can be differentiated from normal regions owing to color differences. For forming this emission difference, the patient is externally given fluorophore-type agents (generally via the oral route).

The first fluorescent thoracoscopy technique was tested in animals in 2002 (52). In this trial, 5-aminolevulinic acid (ALA) was used as the chemical agent, and it was noted that fluorescence revealed $30 \%$ more malignant regions compared with that observed using white light. In two studies based on case series, regions of malignant involvement were observed more clearly under fluorescence in four of 15 mesothelioma patients in one study and in 11 of 20 patients in the other study. In one patient, a region of metastatic malignant involvement, which could not be determined using white light, was found $(53,54)$.

The difference between fluorescent endoscopy and autofluorescent endoscopy is that the patient is not given a chemical agent externally in autofluorescent endoscopy. In malignant tumoral tissues, epithelial thickening and the changes in tumor cell matrix decrease fluorophore concentrations in tumoral regions. In this manner, while white light reflex in tumoral regions decreases, the reflex in the pink-red light wavelength increases in accordance with autofluorescent emission. Malignant tumoral involvement regions appear under pink-red light (51).

In a study in which autofluorescent technique was implemented, 24 patients were examined using both white light and autofluorescent technique simultaneously. The sensitivity of this technique for the detection of malignant lesions was found to be $100 \%$, but its specificity as $75 \%$. False positivity was reported in two of eight patients whose histopathological analysis was "chronic fibrinous pleuritis" (Figure 3) (55).

In the studies comparing fluorescent and autofluorescent techniques, the number of cases is quite limited. Therefore, it is not yet possible to make reliable evaluations. It is clear that studies involving more number of case series are warranted.

\section{"Narrow Band Imaging" in Thoracoscopy}

Narrow Band Imaging (NBI) is a system that can provide an image in the wavelength different from that of the white light; this system uses light wavelength in the $415-540 \mathrm{~nm}$ spectrum, which is suitable for oxyhemoglobin absorption, by eliminating the visual wavelength

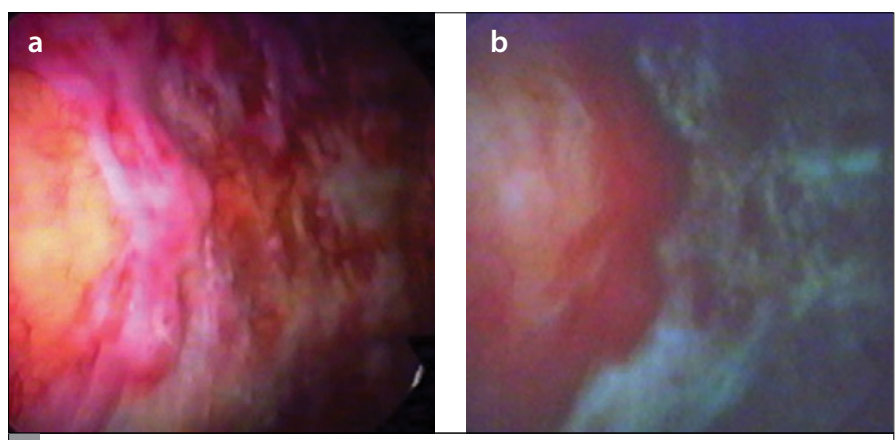

Figure 3. a, b. In normal MT, the regions of mesothelioma in volvement are shown as pink (a), in autofluorescent imaging, the same regions are seen as red (b) 


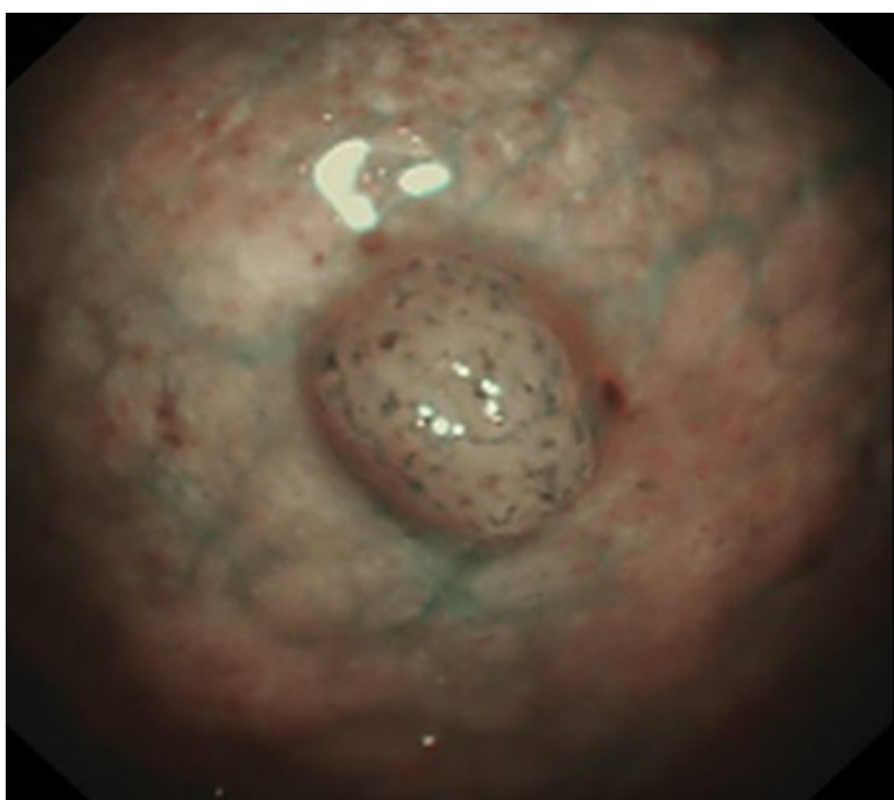

Figure 4. Malignant nodular involvement and abnormal vascular construction in the pleura (narrow band imaging)

spectrum. Thus, the blood vessels in this region become more visible. The expectation of increased vascularization on tumor has been estimated to be an advantage of this system (Figure 4).

Because of the presence of fibrotic tissue layers on the pleura in some mesothelioma cases, the chance of histopathological diagnosis may decrease in the biopsies taken through MT. In such cases, the hypothesis that NBI demonstrates the vascularization better in deep pleural layer was thought to be an advantage, but its superiority over normal thoracoscope with regard to the determination of blood vessels was not detected in a series including 26 cases (56). Further studies on $\mathrm{NBI}$ are needed to be conducted with case series of a larger scale.

\section{Current Practical Medical Thoracoscopy Applications}

One of the two most important problems that must be overcome with regard to MT is that it should be possible to implement the procedure for outpatients and the other is that it should be possible to perform this procedure for patients without pleural fluid.

The performance of MT in ambulatory care conditions will be a significant gain because hospitalization increases costs and patient discomfort as well as causes unnecessary work load. For MT to be performed in outpatients, mini-thoracoscopy and semirigid thoracoscopy have been developed. Probably, both techniques will become more widespread in the coming days. In a recent study conducted with 51 patients, it was demonstrated that normal MT procedure could be safely performed in outpatients (10).

In patients without pleural fluid, VATS under general anesthesia is the diagnostic technique that is essentially preferred. If there is a mass or adequately large nodular lesions in the pleura, biopsy can be performed using tru-cut needle. However, in a significant number of patients, needle biopsy cannot be performed because of the volume and distribution of pleural lesions. In fact, if there is no diffuse adherence between the visceral pleura and parietal pleura, this space can be entered with MT even though pleural fluid does not exist. In a recently conducted study involving MT including a series of 622 patients, it was reported that MT was successfully and safely performed in 29 patients not having pleural fluid, but having a sliding sign (overlapping pleura) on ultrasonography (11). This series will be an important initiative with regard to MT studies.

\section{Education}

A specialist in chest diseases who performs diagnostic and palliative MT should first study the thoracic anatomy in detail. In accordance with the educational process approved by related institutions, he/she must directly participate in at least three procedures with an instructor and then perform at least three procedures under the control of the instructor before starting to implement MT alone. For a specialist in chest diseases to maintain his/her performance, he/she must perform at least 12 MT procedures in a year $(2,3)$. At present, the most important educational need for MT is a model simulation system.

Peer-review: Externally peer-reviewed.

Conflict of Interest: No conflict of interest was declared by the author.

Financial Disclosure: The author declared that this study has received no financial support.

\section{REFERENCES}

1. Loddenkemper R. Medical Thoracoscopy. In: Textbook of pleural diseases. Light RW, Gary Lee YC, editors. London: Hodder Arnold; 2008: 583-97. [CrossRef]

2. Buchanan DR, Neville E. Thoracoscopy for physicians. London: Arnold; 2004: 71-114.

3. Rahman NM, Ali NJ, Brown G, Chapman SJ, Davies RJ, Downer NJ, et al. Local anaesthetic thoracoscopy: British Thoracic Society Pleural Disease Guideline 2010. Thorax 2010; 65 (Suppl 2): ii54-60. [CrossRef]

4. Jacobaeus HC. Über die Möglichkeit die Zystoskopie bei Untersuchung seröser Höhlungen anzuwenden. Münch Med Woch 1910; 57: 2090-2.

5. DeFrancis N, Klosk E, Albano E. Needle biopsy of the parietal pleura; a preliminary report. N Engl J Med 1955; 252: 948-51. [CrossRef]

6. Boutin C, Astoul P, Rey F, Viallat JR. Medical thoracoscopy. Rev Mal Respir 1995; 12: 505-8.

7. Loddenkemper R, Mathur PN, Noppen M, Lee P. Medical Thoracoscopy/ Pleuroscopy. Manual and Atlas. Stuttgart New York: Thieme; 2011. [CrossRef]

8. Mohan A, Chandra S, Agarwal D, Naik S, Munavvar M. Utility of semirigid thoracoscopy in the diagnosis of pleural effusions: a systematic review. J Bronchology Interv Pulmonol 2010; 17: 195-201. [CrossRef]

9. Tassi GF, Marchetti GP, Pinelli V. Minithoracoscopy: a complementary technique for medical thoracoscopy. Respiration 2011; 82: 204-6. [CrossRef]

10. DePew ZS, Wigle D, Mullon JJ, Nichols FC, Deschamps C, Maldonado F. Feasibility and safety of outpatient medical thoracoscopy at a large tertiary medical center: A collaborative medical-surgical initiative. Chest 2014; 146: 398-405. [CrossRef]

11. Marchetti G, Valsecchi A, Indellicati D, Arondi S, Trigiani M, Pinelli V. Ultrasound guided medical thoracoscopy in the absence of pleural effusion. Chest 2015; 147: 1008-12. [CrossRef]

12. Scherpereel A, Astoul $P$, Baas $P$, Berghmans $T$, Clayson $H$, de Vuyst $P$, et al. Guidelines of the European Respiratory Society and the European Society of Thoracic Surgeons for the management of malignant pleural mesothelioma. ERS/ESTS task force. Eur Respir J 2010; 35: 479-95. [CrossRef]

13. Ernst A, Silvestri GA, Johnstone D. Interventional pulmonary procedures: guidelines from the American College of Chest Physicians. Chest 2003; 123: 1693-717. [CrossRef]

14. Türkiye Mezotelyoma Çalışma Grubu. Malign Plevral Mezotelyoma Türkiye Standartlar Rehberi. Eskişehir: ESOGÜ-APKAM; 2014.

15. Astoul P, Tassi G, Tschopp JM. Thoracoscopy for pulmonologists: a didactical approach. London: Springer, 2013.

16. Swierenga A. Atlas of thoracoscopy. Rhein: Boehringer Ingelheim; 1978.

17. Brandt $\mathrm{HJ}$, Loddenkemper R, Mai J. Atlas of diagnostic thoracoscopy. Indications - Technique. New York: Thieme; 1985.

18. Alcozer G, Dorigoni A . La toracoscopia diagnostica. Firenze: Nardini; 1984. 
19. Quetglas FS, Velasquez AS, Pujol JL. La toracoscopia. Madrid: Jarpyo; 1985.

20. Boutin C, Viallat JR, Aelony Y. Practical thoracoscopy. Berlin: Springer; 1991. [CrossRef]

21. Plevra hastalıklarında torakoskopinin değeri. Uzmanlık Tezi; Dicle Üniversitesi Tıp Fakültesi, Diyarbakır, 1979.

22. Artvinli M, Sahin AA, Altinörs M, Baris YI. Thoracoscopy in the diagnosis of environmental natural mineral fiber-induced pleural diseases. Poumon Coeur 1981; 37: 245-7.

23. Artvinli.M, Ardıç S, Şahin AA. Plevra hastalıkları tanısında torakoskopi. Türkiye Klinikleri Tıp Bil Araş Derg 1983; 1: 81-4.

24. Metintas M, Ak G, Dundar E, Yildirim H, Ozkan R, Kurt E, et al. Medical thoracoscopy vs CT scan-guided Abrams pleural needle biopsy for diagnosis of patients with pleural effusions: a randomized, controlled trial. Chest 2010; 137: 1362-8. [CrossRef]

25. Metintas M, Ak G, Cadirci O, Yildirim H, Dundar E, Metintas S. Outcome of patients diagnosed with fibrinous pleuritis after medical thoracoscopy. Respir Med 2012; 106: 1177-83. [CrossRef]

26. Metintas M, Ak G, Yildirim H, Danacioglu S, Dundar E, Metintas S. The safety of medical thoracoscopy in a group at high risk for complications. J Bronchology Interv Pulmonol 2013; 20: 224-31. [CrossRef]

27. Karasulu AL, Dalar L, Altin S, Bakan ND, Sökücü SN. Semirigid thoracoscopy in the diagnosis of pleural effusion: first four cases in Turkey]. Tuberk Toraks 2011; 59: 188-93. [CrossRef]

28. Lee P, Colt HG. State of the art: pleuroscopy. J Thorac Oncol 2007; 2: 66370. [CrossRef]

29. Tsakiridis K, Zarogoulidis P. An interview between a pulmonologist and a thoracic surgeon-Pleuroscopy: the reappearance of an old definition. J Thorac Dis 2013; 5(Suppl 4): S449-51.

30. Rodrigues-Panadero F. Medical thoracoscopy. Respiration 2008; 76: 363-72. [CrossRef]

31. Casal RF, Eapen GA, Morice RC, Jimenez CA. Medical thoracoscopy. Curr Opin Pulm Med 2009; 15: 313-20. [CrossRef]

32. Janssen JP. Why you do or do not need thoracoscopy. Eur Respir Rev 2010; 19: 213-16. [CrossRef]

33. Medford AR, Bennett JA, Free CM, Agrawal S. Current status of medical pleuroscopy. Clin Chest Med 2010; 31: 165-72. [CrossRef]

34. Rodriguez-Panadero F, Janssen JP, Astoul P. Thoracoscopy: general overview and place in the diagnosis and management of pleural effusion. Eur Respir J 2006; 28: 409-22. [CrossRef]

35. Metintas M, Ak G, Dundar E, Yildirim H, Ozkan R, Kurt E, et al. Medical thoracoscopy vs CT scan-guided Abrams pleural needle biopsy for diagnosis of patients with pleural effusions: a randomized, controlled trial. Chest 2010; 137: 1362-8. [CrossRef]

36. Loddenkemper R, Schonfeld N. Medical thoracoscopy. Curr Opin Pulm Med 1998; 4: 235-8. [CrossRef]

37. Wrightson JM, Davies HE. Outcome of patients with nonspecific pleuritis at thoracoscopy. Curr Opin Pulm Med 2011; 17: 242-6. [CrossRef]

38. Ravaglia C, Gurioli C, Tomassetti S, Casoni GL, Romagnoli M, Gurioli C, et al. Is medical thoracoscopy efficient in the management of multiloculated and organized thoracic empyema? Respiration 2012; 84: 219-24. [CrossRef]
39. Tassi GF, Marchetti GP, Pinelli V, Chiari S. Practical management of pleural empyema. Monaldi Arch Chest Dis 2010; 73: 124-9.

40. West SD, Davies RJO, Lee YC. Pleurodesis for malignant pleural effusions: current controversies and variations in practices. Curr Opin Pulm Med 2004, 10: 305-10. [CrossRef]

41. Dresler CM, Olak J, Herndon JE 2nd, Richards WG, Scalzetti E, Fleishman $\mathrm{SB}$, et al. Phase III intergroup study of talc poudrage vs talc slurry sclerosis for malignant pleural effusion. Chest 2005; 127: 909-15. [CrossRef]

42. Kern L, Robert J, Brutsche M. Management of parapneumonic effusion and empyema: medical thoracoscopy and surgical approach. Respiration 2011; 82: 193-6. [CrossRef]

43. Bhatnagar R, Maskell NA. Treatment of complicated pleural effusions in 2013. Clin Chest Med 2013; 34: 47-62. [CrossRef]

44. Brutsche MH, Tassi GF, Györik S, Gökcimen M, Renard C, Marchetti GP, et al. Treatment of sonographically stratified multiloculated thoracic empyema by medical thoracoscopy. Chest 2005; 128: 3303-9. [CrossRef]

45. Maskell NA, Davies CW, Nunn Al, Hedley EL, Gleeson FV, Miller R, et al. U.K. Controlled trial of intrapleural streptokinase for pleural infection. $N$ Eng J Med 2005; 352: 865-74. [CrossRef]

46. Rahman NM, Maskell NA, West A, Teoh R, Arnold A, Mackinlay C, et al. Intrapleural use of tissue plasminogen activator and DNAse in pleural infection. N Eng J Med 2011; 365: 518-26. [CrossRef]

47. Cassina PC, Hauser M, Hillejan L, Greschuchna D, Stamatis G. Video-assisted thoracoscopy in the treatment of pleural empyema: stage-based management and outcome. J Thorac Cardiovasc Surg 1999; 117: 234-8. [CrossRef]

48. Mohan A, Naik S, Naseer R, Boon C, Mills J, Pandey RM, et al. Performance characteristics of semirigid thoracoscopy in pleural effusions of undetermined etiology. J Bronchol Intervent Pulmonol 2010; 17: 289-94. [CrossRef]

49. Mohan A, Chandra S, Agarwal D, Naik S, Munavvar M. Utility of semirigid thoracoscopy in the diagnosis of pleural effusions. A systemic review. J Bronchol Intervent Pulmonol 2010; 17: 195-201. [CrossRef]

50. Tassi G, Marchetti G. Minithoracoscopy: a less invasive approach to thoracoscopy. Chest 2003; 124: 1975-7. [CrossRef]

51. Jannssen J. Autofluorescence thoracoscopy. Iç̧: Metintas M, Selçuk TZ, Yılmaz A. Girişimsel pulmonoloji. Ankara: Rotatıp, 2014; ss: 743-747.

52. Prosst RL, Winkler S, Boehm E, Gahlen J. Thoracoscopic fluorescence diagnosis (TFD) of pleural malignancies: experimental studies. Thorax 2002; 57: 1005-9. [CrossRef]

53. Baas $P$, Triesscheijn M, Burgers $S$, van Pel R, Stewart F, Aalders M. Fluorescence detection of pleural malignancies using 5 -aminolaevulinic acid. Chest 2006; 129: 718-24. [CrossRef]

54. Pikin O, Filonenko E, Mironenko D, Vursol D, Amiraliev A. Fluorescence thoracoscopy in the detection of pleural malignancy. Eur J Cardiothorac Surg 2012; 41: 649-52. [CrossRef]

55. Chrysanthidis MG, Janssen JP. Autofluorescence videothoracoscopy in exudative pleural effusions: preliminary results. Eur Respir J 2005; 26 989-92. [CrossRef]

56. Schönfeld N, Schwarz C, Kollmeier J, Blum T, Bauer TT, Ott S. Narrow band imaging (NBI) during medical thoracoscopy: first impressions. J Occup Med Toxicol 2009; 4: 24-9.[CrossRef] 